\title{
Depletion of thymopoietin inhibits proliferation and induces cell cycle arrest/apoptosis in glioblastoma cells
}

\author{
Lin Zhang ${ }^{\dagger}$, Gan Wang, Shiwen Chen, Jun Ding ${ }^{\dagger}$, Shiming Ju, Heli Cao and Hengli Tian ${ }^{*}$
}

\begin{abstract}
Background: Glioblastoma (GBM) is the most malignant nervous system tumor with an almost $100 \%$ recurrence rate. Thymopoietin (TMPO) has been demonstrated to be upregulated in various tumors, including lung cancer, breast cancer, and so on, but its role in GBM has not been reported. This study was aimed to determine the role of TMPO in GBM.
\end{abstract}

Methods: Publicly available Oncomine dataset analysis was used to explore the expression level of TMPO in GBM specimens. Then the expression of TMPO was knocked down in GBM cells using lentiviral system, and the knockdown efficacy was further validated by real-time quantitative PCR and western blot analysis. Furthermore, the effects of TMPO silencing on GBM cell proliferation and apoptosis were examined by MTT, colony formation, and flow cytometry analysis. Meanwhile, the expression of apoptotic markers caspase-3 and poly(ADP-ribose) polymerase (PARP) were investigated by western blot analysis.

Results: This study observed that the expression of TMPO in GBM specimens was remarkably higher than that in normal brain specimens. Moreover, knockdown of TMPO could significantly inhibit cell proliferation and arrest cell cycle progression at the G2/M phase. It also found that TMPO knockdown promoted cell apoptosis by upregulation of the cleavage of caspase-3 and PARP protein levels which are the markers of apoptosis.

Conclusions: The results suggested TMPO might be a novel therapeutic target for GBM.

Keywords: TMPO, Glioblastoma, Cell proliferation, Apoptosis

\section{Background}

Glioblastoma (GBM) (World Health Organization grade IV astrocytoma) is the most frequent and most malignant brain tumor. The standard therapy method for newly diagnosed GBM is surgery followed by radiotherapy plus temozolomide chemotherapy [1]. But the GBM is still along with a $100 \%$ recurrence rate and about a $5 \% 5$-year survival rate [2, 3]. Researchers are screening new drugs for GBM treatment, such as bevacizumab, which is a humanized monoclonal antibody against vascular endothelial growth factor A (VEGF-A), but it cannot improve overall survival in patients with GBM; the adverse events such as increased symptom severity are more serious $[4,5]$. So the

\footnotetext{
*Correspondence: tianhlsh@126.com; tianhlsh1123@126.com

${ }^{\dagger}$ Equal contributors

Department of Neurosurgery, Shanghai Jiao Tong University Affiliated Sixth People's Hospital, School of Medicine, Shanghai Jiao Tong University, No. 600 Yishan Road, Xuhui District, Shanghai 200233, China
}

development of new therapeutic targets is essential for GBM therapy.

Thymopoietin (TMPO) is also named as laminaassociated polypeptide 2 (LAP2) and has six alternatively spliced isoforms with different functions [6]. TMPO can interact with lamins and BAF to regulate the organization of the nuclear structure and the dynamics of the cell cycle [7]. Recently, the role of TMPO in cancer biology has been reported [8]. LAP2 $\beta$ is upregulated in the rapidly proliferating cells of various hematological malignancies but is normally expressed in the slowly proliferating cells of chronic malignant hematological diseases [9]. LAP2 $\beta$ is upregulated in digestive tract tumor tissues and cells; its knockdown could inhibit migration, invasion, and metastasis but has no effect on cell proliferation. In pancreatic cancer cells, knockdown of LAP2 $\beta$ not only inhibits cell 
proliferation but also suppresses migration, invasion, and metastasis [10].

However, the role of TMPO in GBM has not been reported until now. In this study, short hairpin RNA (shRNA) for TMPO was used to knock down TMPO in GBM cells and the MTT assay and colony formation assay were used to determine the effect of TMPO on cell proliferation. Finally, the approach of TMPO that regulated cell proliferation, cell cycle progression, or apoptosis was determined. In addition, the knockdown of TMPO reduced the cell proliferation rate caused by promoting apoptosis.

\section{Methods}

\section{Data mining and Oncomine analysis}

A series of microarray datasets for glioblastoma were retrieved from the public Oncomine cancer microarray database (www.oncomine.org) to investigate TMPO expression in glioblastoma [11]. Differential expressions of TMPO between glioblastoma and normal tissues were retrieved from seven different databases, including French Brain [12], Liang Brain [13], Murat Brain [14], TCGA Brain (The Cancer Genome Atlas-Glioblastoma Multiforme Gene Expression Data, http://tcga-data.nci. nih.gov/tcga/), Shai Brain [15], Sun Brain [16], and Pomeroy Brain [17]. The TMPO gene expression in glioblastoma was compared with normal brain tissues according to the previously described [18].

\section{Cell lines and culture}

GBM cells including U251 and U87 and human embryonic kidney cell line 293T were purchased from the Cell Bank of Chinese of Science (Shanghai, China). U251 was cultured in DMEM (SH30243.01B, HyClone, USA) supplemented with $10 \%$ fetal bovine serum (FBS, S1810, Biowest, Spain). U87 was cultured in EMEM (SH30024.01B, HyClone, USA) supplemented with FBS, 1 \% PEP, and $1 \%$ NEAA. 293T cells which were used to package lentivirus were cultured in DMEM supplemented with 10 \% FBS. All cells were maintained in a humidified atmosphere at $37^{\circ} \mathrm{C}$ with $5 \% \mathrm{CO}_{2}$.

\section{Vector construction and virus infection}

The sequences (S1: 5'-GCACAGATTCTTAGCTCAGAT3', S2: 5'-CTTGTGAAATACGGAGTGAAT-3') were used as the target sequence to downregulate the TMPO (NM_003276.2) level, and shRNA oligos for TMPO were cloned into the pFH-L lentiviral vector (Hollybio, Shanghai, China) which carried green fluorescent protein (GFP) and were indicated as TMPO-shRNA and TMPO-shRNA(S2). The sequence (5'-TTCTCCGAACGTGTCACGT-3') was used as a scramble control and cloned into the pFH-L vector (Con-shRNA). Then the shRNA plasmid and two pHelper plasmids pVSVG-I and pCMV $\Delta$ R8.92 were co- transfected into $293 \mathrm{~T}$ cells using the calcium phosphate transfection protocol. The viral supernatants were collected and filtered at $48 \mathrm{~h}$ after transfection. For lentivirus infection, U251 and U87 cells were seeded in six-well plates at a density of $7 \times 10^{4}$ cells/well and $5 \times 10^{4}$ cells/ well, respectively. Subsequently, the lentiviruses containing TMPO-shRNA, TMPO-shRNA(S2), or Con-shRNA were transduced into U251 and U87 cells at 10 and 8 MOI (multiplicity of infection), respectively. After a 72-h infection, the infection efficiency was determined by observing the GFP expression under a fluorescence microscope.

\section{RNA extraction and real-time quantitative PCR}

Total RNA was extracted using RNAiso Plus reagent (Takara, Japan) according to the manufacturer's instructions and synthesized into complementary DNA (cDNA) using HiScript 1st Strand cDNA Synthesis Kit (Vazyme, China). TMPO expression was quantified using HiScript ${ }^{\circ}$ Q RT SuperMix for qPCR (Vazyme, China) in a BioRad Connet Real-Time PCR platform and performed in triplicates. Actin was used as an endogenous control for normalization. The relative expression of TMPO was calculated as using the $2^{-\Delta \Delta C t}$ method [19]. Ct was the threshold cycle of each transcript. The real-time quantitative PCR primers were shown as follows: TMPO: forward, 5'-TGCTCGCCTCCTGCCTG TAG-3' and reverse, 5'-GACACAAAGCCAAGCCAGA CC-3'; Actin: forward, 5'-GTGGACATCCGCAAAGAC$3^{\prime}$ and reverse, $5^{\prime}$-AAAGGGTGTAACGCAACTA-3'.

\section{Western blot}

Total protein was extracted from cells using RIPA buffer $(50 \mathrm{mM}$ Tris- $\mathrm{HCl}$, at $\mathrm{pH} 8.0,150 \mathrm{mM} \mathrm{NaCl}, 5 \mathrm{mM}$ EDTA, $0.1 \%$ SDS, and $1 \%$ NP-40). The protein samples $(30 \mu \mathrm{g} /$ well $)$ were loaded and separated by $10 \%$ SDS-polyacrylamide gel electrophoresis (PAGE). Western blot was performed according to the previous report [20]. Anti-TMPO (1:1000, 14651-1-AP, Proteintech, USA), poly(ADP-ribose) polymerase (PARP;1:1000, \#9542, Cell Signaling Technology, USA), and caspase-3 (1:500, Cell Signaling Technology, USA) antibodies were used. An anti-GAPDH antibody (1:500000, 10494-1-AP, Proteintech, USA) was used as the loading control. The secondary antibody used was horseradish peroxidase (HRP)-conjugated goat anti-rabbit antibody (1:5000, SC-2054, Santa Cruz, USA).

\section{Cell proliferation analysis by MTT}

After lentivirus infection for $72 \mathrm{~h}$, a total density of 2500 cells/well for U251 cells or 3000 cells/well for U87 cells were reseeded in a 96-well plate. The cell viability was determined at five different timing points (days 1, 2, 3, 4, and 5) using the MTT assay. Briefly, $20 \mu \mathrm{l}$ of MTT (Sigma, USA) solution was added to the 
wells and incubated for $4 \mathrm{~h}$ at $37^{\circ} \mathrm{C}$. Then $100 \mu \mathrm{l}$ acidic isopropanol solution (10\% SDS, $5 \%$ isopropanol, and $0.01 \mathrm{~mol} / \mathrm{l} \mathrm{HCl}$ ) was added and incubated overnight to solubilize the formazan. The optical density (OD) value was measured at $570 \mathrm{~nm}$ using a microplate reader (Epoch, BioTek, USA). All experiments were performed in triplicates.

\section{Colony formation assay}

Colony formation assay was carried out according to the previous report [21]. Briefly, U251 cells stably transduced lentivirus were reseeded on six-well plates and cultured for 12 days at a density of 600 cells/well. Then colonies were fixed using $4 \%$ paraformaldehyde for $5 \mathrm{~min}$ and then stained with $1 \%$ crystal violet for $30 \mathrm{~s}$. The cells were photographed, and the number of colonies was counted.

\section{Flow cytometric analysis of the cell cycle}

After lentivirus infection for 5 days, a total density of 80,000 cells/dish for U251 cells were reseeded in 6-cm dishes and continued to culture for $72 \mathrm{~h}$. Then cells were collected, washed with pre-cooling PBS, and fixed with cooling $70 \%$ ethanol overnight at $4{ }^{\circ} \mathrm{C}$. After washing twice with pre-cooling PBS, the cells were resuspended and incubated in $500 \mu \mathrm{l} \mathrm{PBS}$ containing $50 \mu \mathrm{g} / \mathrm{ml}$ propidium iodide solution (PI) and $100 \mu \mathrm{g} / \mathrm{ml}$ RNase for $30 \mathrm{~min}$ at room temperature. Finally, the cells were analyzed on a FACS Calibur cytometer (BD, USA). Data were analyzed using CellQuest software.

\section{Apoptosis analysis}

Apoptosis analysis was performed using the Annexin VAPC/7-AAD apoptosis kit (KeyGEN Biotech, Nanjing, China) according to the manufacturer's instructions. Cells were analyzed on a FACS Calibur cytometer (BD, USA). Data were analyzed using CellQuest software.

\section{Statistical analysis}

Statistical analysis was performed using SPSS 19 (SPSS Inc., USA). Results are shown as the mean \pm standard deviation (STDEV) for at least three repeated individual experiments for each group. Statistical differences were determined using Student's $t$ test for independent samples. $p<0.05$ was considered statistically significant.

\section{Results}

TMPO mRNA expression was elevated in glioblastoma

To analyze the expression level of TMPO in GBM, the publicly available Oncomine cancer microarray database was excavated. As shown in Fig. 1a, the French Brain dataset showed that TMPO expression is significantly elevated in oligodendroglioma $(n=23, p=5.62 \mathrm{E}-4)$ compared with the normal tissues. Comparing with normal brain tissues, TMPO expression in glioblastoma tissues is much higher as shown in three different microarray datasets including the Liang Brain dataset $(n=30, p=0.015)$, the Murat Brain dataset $(n=80, p=0.010)$, and the TCGA Brain dataset ( $n=542, p=1.29 \mathrm{E}-6)$ (Fig. 1b-d). Also, TMPO expression was significantly increased in glioblastoma tissues $(n=27, p=0.002)$ and oligodendroglioma tissues $(n=3, p=0.043)$ in the Shai Brain dataset (Fig. 1e).

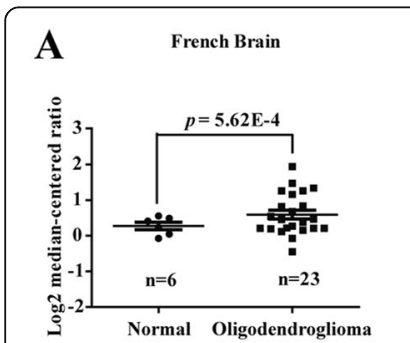

$\mathbf{E}$

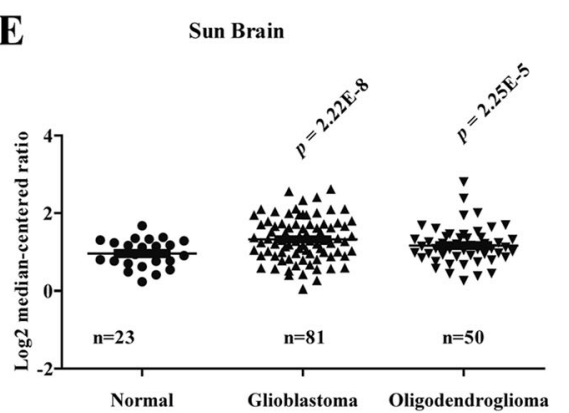

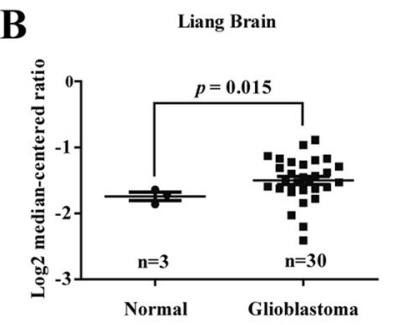

F
C

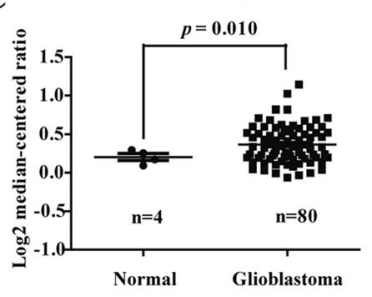

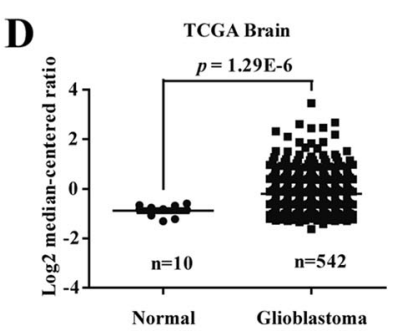

G
Pomeroy Brain
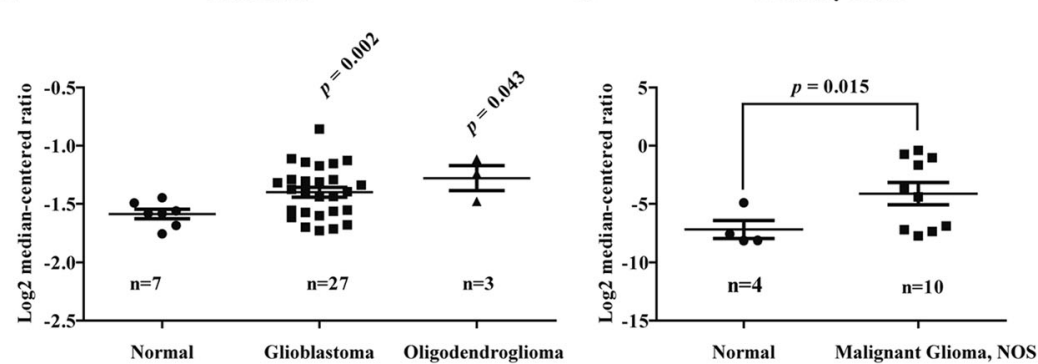

Fig. 1 Upregulation of TMPO mRNA in GBM was revealed by Oncomine database. The expression of the TMPO gene was extracted and analyzed from a the French Brain dataset, $\mathbf{b}$ the Liang Brain dataset, $\mathbf{c}$ the Murat Brain dataset, $\mathbf{d}$ the TCGA Brain dataset, e the Shai Brain dataset, $\mathbf{f}$ the Sun Brain dataset, and $\mathbf{g}$ the Pomeroy Brain dataset shown as scatterplots 
Furthermore, the Sun Brain dataset revealed that TMPO was upregulated in glioblastoma tissues $(n=81$, $p=2.22 \mathrm{E}-8)$ and oligodendroglioma tissues $(n=50, p=$ $2.25 \mathrm{E}-5)$ compared with normal brain tissues (Fig. 1f). The results of the Pomeroy Brain dataset were similar to the abovementioned results that the expression level of TMPO was also significantly higher in malignant glioma $(n=10, p=0.015)$ than that in the normal tissues (Fig. 1g). These data suggested that TMPO might play an underlying carcinogenesis in glioblastoma.

\section{TMPO-shRNA could knock down TMPO effectively}

To determine the role of TMPO in GBM, TMPOshRNA was used to knock down TMPO in U251 and U87. Quantitative real-time PCR revealed that the knockdown efficiency of TMPO in the messenger RNA (mRNA) level was about $60 \%$ in U251 cells and up to 90 \% in U87 cells (Fig. 2a). As shown in Fig. 2b, TMPO protein levels were reduced in both U251 and U87 cells infected with TMPO-shRNA by western blot assay. Moreover, western blot analysis also confirmed that the TMPO protein level in the TMPO-shRNA(S2) group was significantly decreased compared with that in the Con-shRNA group in U251 cells (Fig. 2c). These results suggested TMPO-shRNA constructed successfully significantly suppressed TMPO expression both at the mRNA and protein levels.

\section{Knockdown of TMPO inhibited cell proliferation}

To determine whether TMPO affects GBM cell proliferative abilities, MTT and colony formation assays were carried out. As shown in Fig. 3a, b, the growth rate of the TMPO-shRNA group was significantly suppressed by 37.3 and $63.5 \%$ compared to the Con-shRNA group on day 5 in U251 (OD value, $1.66 \pm 0.04$ vs. $2.65 \pm 0.08$, $p<0.001$ ) and U87 (OD value, $0.77 \pm 0.03$ vs. $2.10 \pm 0.08$, $p<0.001)$ cells, respectively. Similarly, compared with the Con-shRNA group, the proliferative ability on day 5 in the TMPO-shRNA(S2) group was also observably inhibited by $58.9 \%$ in the U251 cells (OD value, $2.58 \pm$ 0.16 vs. $6.26 \pm 0.30, p<0.001$, Fig. $3 c)$. Moreover, the colony formation ability of U251 cells infected with the TMPO-shRNA or the TMPO-shRNA(S2) group was further explored, and the size and number of the colony were both smaller in both the TMPO-shRNA and TMPOshRNA(S2) groups than those in the Con-shRNA group (Fig. 3d). In comparison with the Con-shRNA group, the numbers of colonies were markedly lower in the TMPOshRNA group ( $28 \pm 6$ vs. $128 \pm 17, p<0.01)$ and the TMPO-shRNA(S2) group ( $4 \pm 1$ vs. $133 \pm 5, p<0.001)$ in the U251 cells (Fig. 3e). These results suggested that knockdown of TMPO could inhibit the proliferation and colony formation abilities of GBM cells.

\section{Knockdown of TMPO arrested the cell cycle at the G2/M phase}

The approach of TMPO that regulated cell proliferation was further demonstrated. Cell cycle analysis was performed by flow cytometry in U251 cells after TMPO knockdown (Fig. 4a, d). As shown in Fig. 4b, the knockdown of TMPO in U251 cells decreased the population of the G0/G1 phase $(51.2 \pm 0.3 \%$ vs. $61.8 \pm 0.1 \%, p<$ 0.001 ) and increased the population of the $\mathrm{G} 2 / \mathrm{M}$ phase $(32.3 \pm 0.7 \%$ vs. $21.1 \pm 0.3 \%, p<0.001)$ in comparison with the Con-shRNA group. Similar to the results of the TMPO-shRNA group in the U251 cells, a visible decrease in the cell proportion in the G0/G1 phase $(49.5 \pm$ $1.4 \%$ vs. $63.5 \pm 0.9 \%, p<0.001)$ was observed but an increase in the G2/M phase $(18.9 \pm 2.1 \%$ vs. $10.4 \pm 0.5 \%$, $p<0.05)$ in the TMPO-shRNA(S2) group compared with the Con-shRNA group (Fig. 4d). But the S phase population did not change in both the TMPO-shRNA and TMPO-shRNA(S2) groups. This suggested the cell cycle was arrested at the G2/M phase by TMPO knockdown. Furthermore, the apoptotic population of U251 cells in the sub-G1 phase was significantly increased in both the

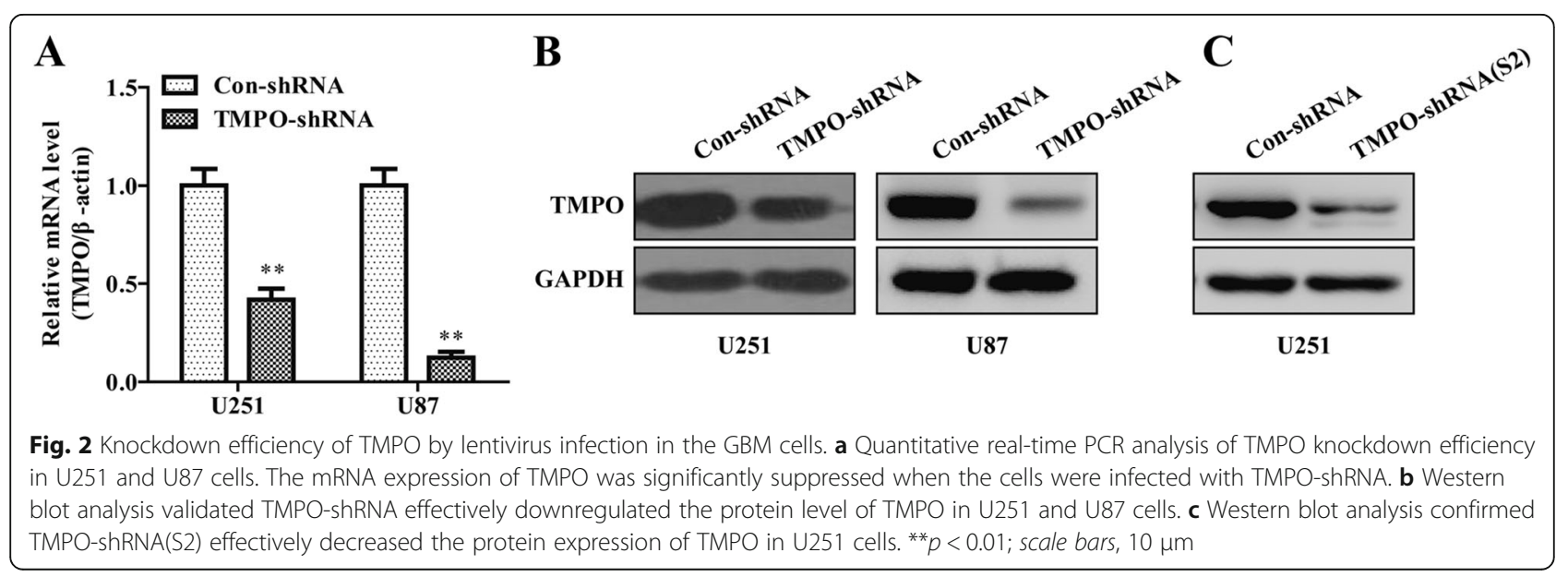




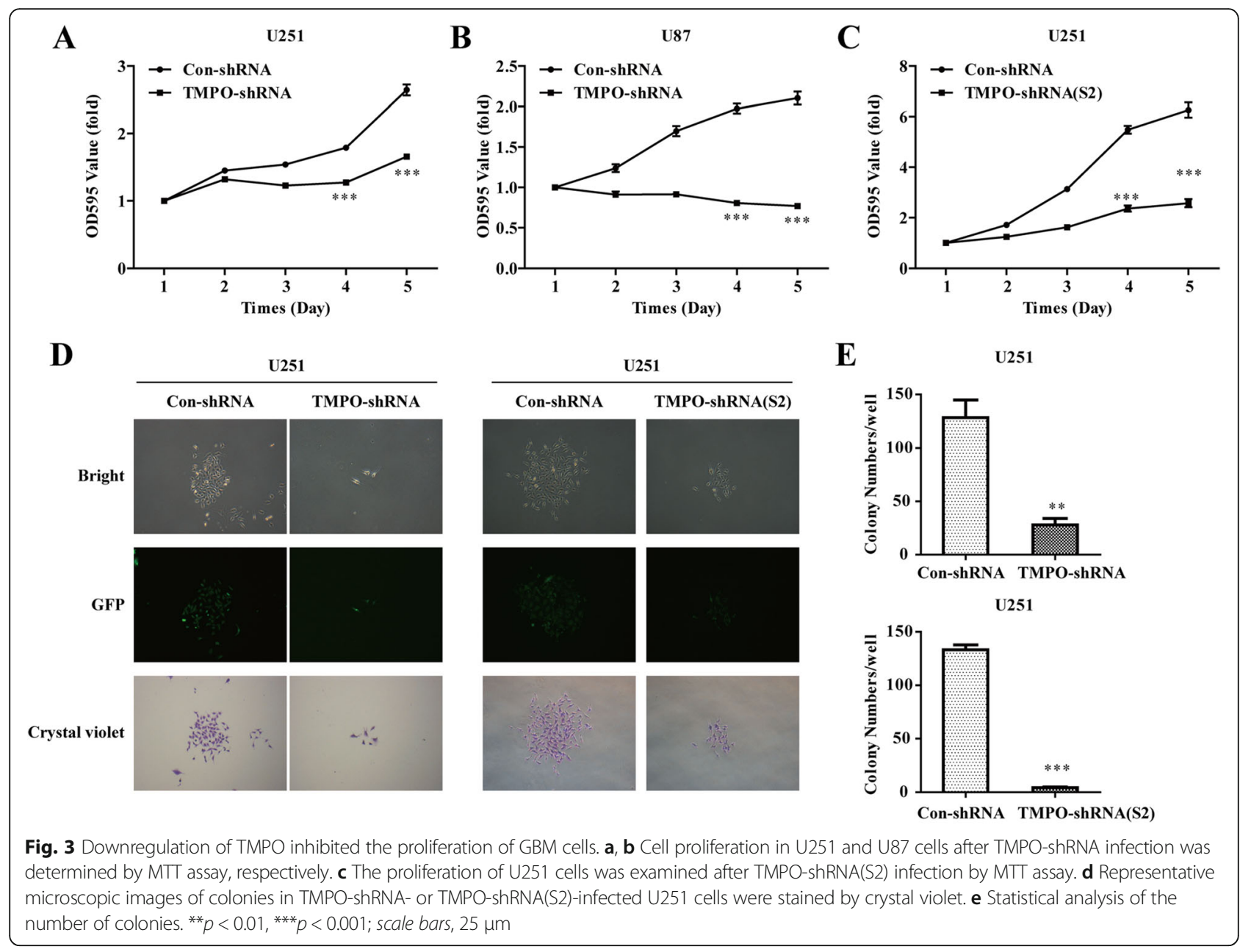

TMPO-shRNA $(1.9 \pm 0.1 \%$ vs. $0.3 \pm 0.0 \%, p<0.001)$ and TMPO-shRNA(S2) groups $(24.2 \pm 0.8 \%$ vs. $7.0 \pm 2.0 \%$, $p<0.01)$ in comparison with the Con-shRNA groups (Fig. 4c, f). These results suggested that TMPO knockdown could inhibit GBM cell growth via inducing cell cycle arrest.

\section{Knockdown of TMPO promoted cell apoptosis}

The effect of TMPO silencing on cell apoptosis was further confirmed using an apoptosis detection kit, and it was found that knockdown of TMPO in U251 cells increased early apoptotic cells (Annexin $\mathrm{V}^{+} / 7-\mathrm{AAD}^{-}$) from $2.7 \pm 0.2 \%$ to $62.2 \pm 0.5 \%(p<0.001)$ and late apoptotic cells (Annexin $\mathrm{V}^{+} / 7-\mathrm{AAD}^{+}$) from $3.1 \pm 0.0 \%$ to $24.82 \pm 0.5 \%(p<0.001)$ and increased nearly 15 -fold the total cell apoptotic population of the TMPO-shRNA group compared to the Con-shRNA group $(p<0.001)$ (Fig. 5a, c). Moreover, the cell percentage was more in the early $(32.4 \pm 2.1 \%$ vs. $1.4 \pm 0.4 \%, p<0.01)$ and late $(14.1$ $\pm 1.7 \%$ vs. $0.0 \pm 0.0 \%, p<0.01)$ apoptosis in the TMPOshRNA(S2) group than in the Con-shRNA group, and there was an over-32-fold increase in the total cell apoptotic population of the TMPO-shRNA(S2) group compared to the Con-shRNA group $(p<0.001)$ (Fig. 5b, d). The results revealed that TMPO silencing produced a strong cell apoptotic effect in GBM cells.

To explore the role of related cell apoptotic molecules in the knockdown of TMPO-induced cell apoptosis, the effect of TMPO silencing on two classical cell apoptotic molecules caspase-3 and PARP was examined by western blot assay. Caspase- 3 is a key executioner of apoptosis and can break many key proteins for apoptosis such as poly(ADP-ribose) polymerase (PARP) [22, 23]. Cleavage of PARP is a marker for cell apoptosis [24]. As shown in Fig. 5e, the expressions of cleaved caspase-3 and cleaved PARP were remarkably increased once TMPO was knocked down. Taken together, the results suggested that TMPO knockdown in U251 cells promoted cell apoptosis due to the upregulation of cleaved caspase- 3 and PARP expression.

\section{Discussion}

In the present study, the role of TMPO in GBM was investigated and it was found that TMPO was overexpressed 

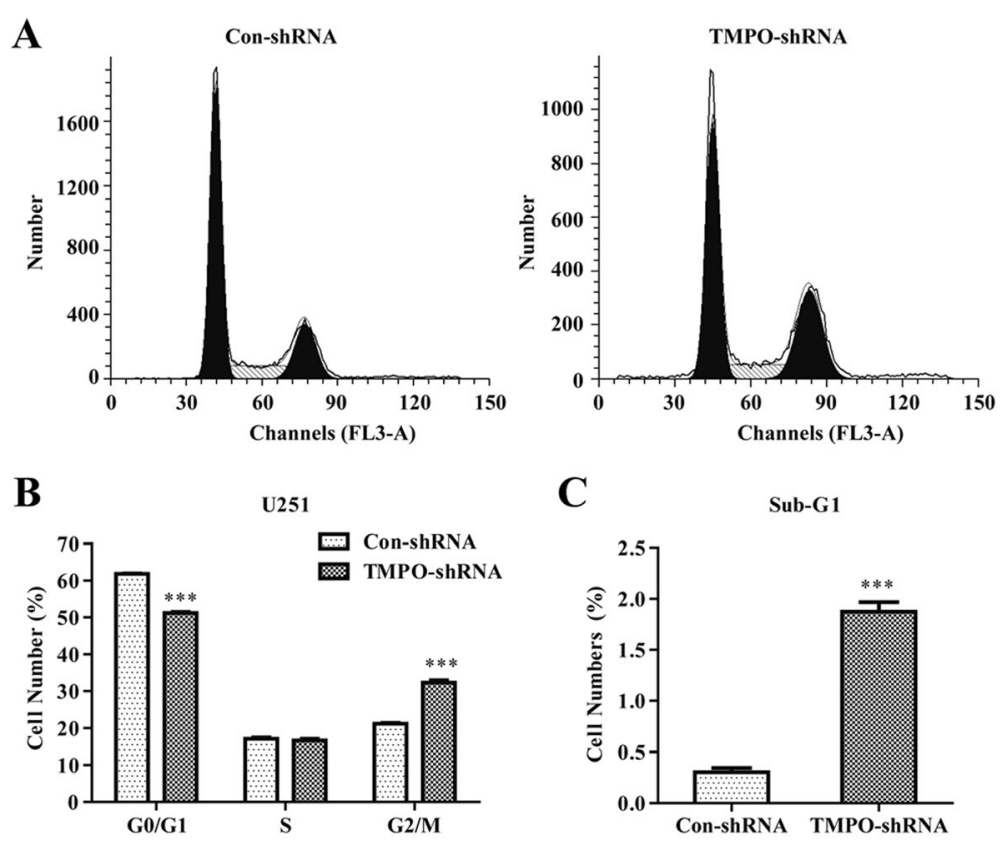

C
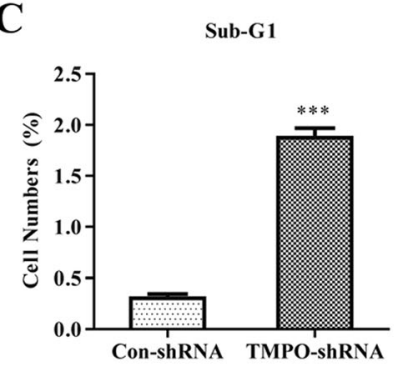

D

Con-shRNA
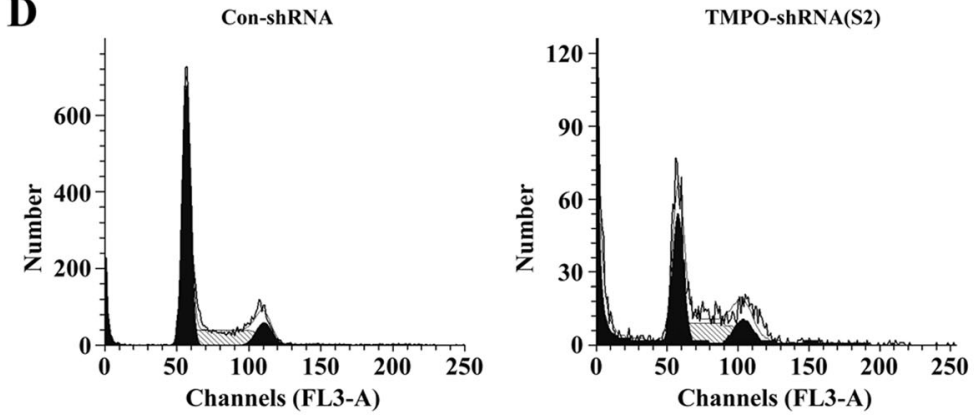

$\mathbf{E}$

U251

$\mathbf{F}$

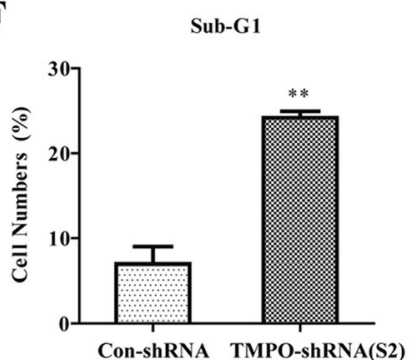

Fig. 4 Downregulation of TMPO arrested the cell cycle of U251 cells. a, d The cell cycle distribution determined by flow cytometer. b, e Statistical analysis of the cell cycle in the U251 cells with TMPO knockdown. $\mathbf{c}$, $\mathbf{f}$ The respective proportion of sub-G1 phase cells. ${ }^{*} p<0.05,{ }^{* *} p<0.01,{ }^{* * *} p<0.001$

in GBM tissues. By knockdown of the TMPO expression, cell proliferation was suppressed by the MTT and colony formation assays. In addition, when TMPO was downregulated, the percentage of the $\mathrm{S}$ phase population did not change, the percentage of G0/G1 was significantly reduced, and the percentage of $\mathrm{G} 2 / \mathrm{M}$ was significantly increased, which suggested that the cell cycle was arrested at the G2/M phase after treatment with TMPO-shRNA. This might be because TMPO regulates nuclear assembly in the mitosis; knockdown of TMPO reduced the rate of nuclear assembly [25].

It has been demonstrated that there is a close relation between cell cycle arrest and DNA damage response $[26,27]$. Accumulation of the $G 2 / M$ phase population is prominently related with apoptosis [28]. The finding that knockdown of TMPO induced cell cycle arrest at the G2/M phase prompted us to examine whether apoptosis occurred in U251 cells. As expected, knockdown of TMPO 


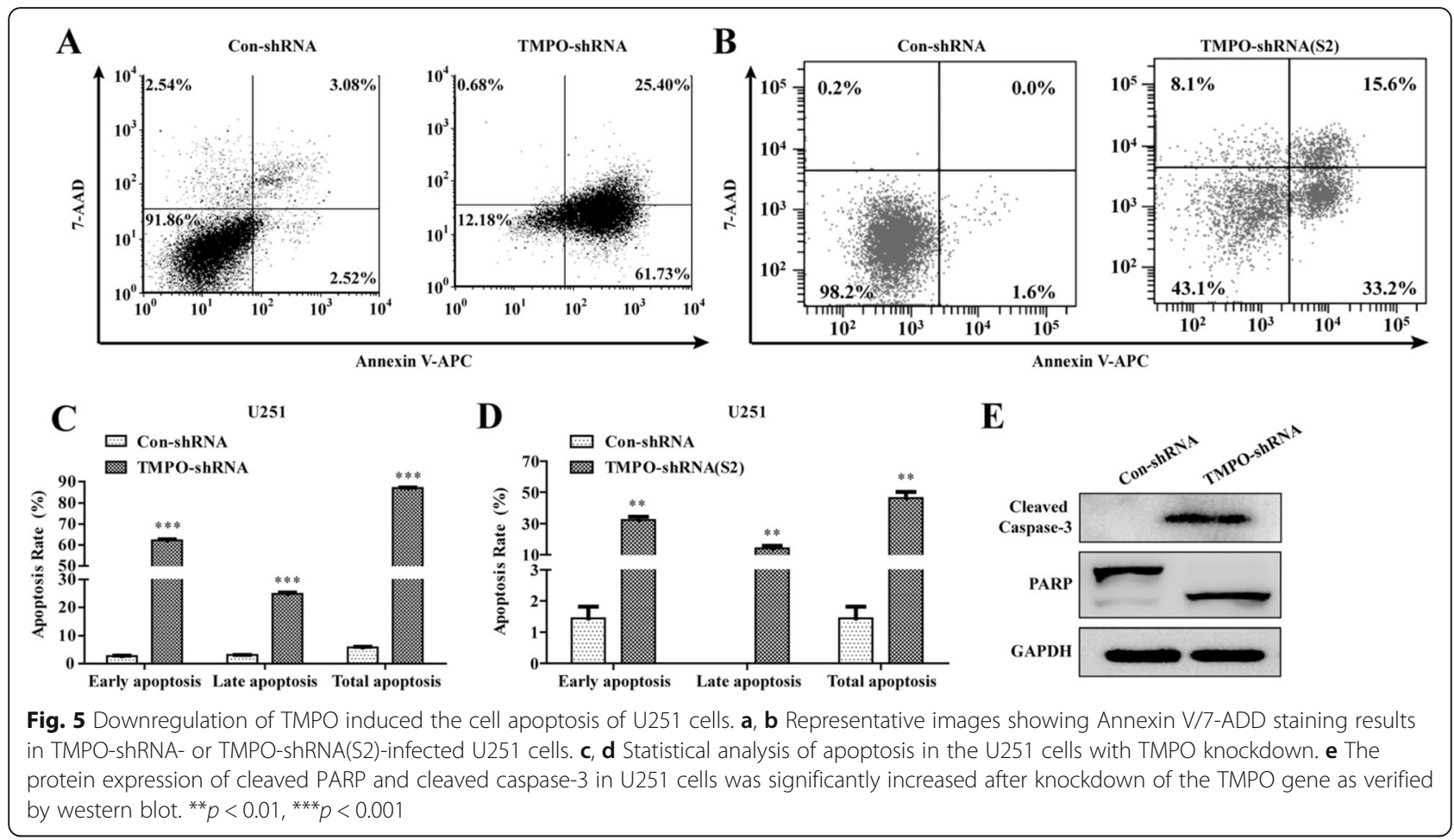

significantly elevated the percentage of cells in early apoptotic and late apoptotic stages. Western blot further suggested knockdown of TMPO increased the cleavage of caspase- 3 and PARP expression. Caspase activation plays a critical role in apoptosis and is divided into two types: initiator caspases (caspases-2, 8, 9, 10) and effector caspases (caspases-3, 6, 7). Both the intrinsic pathway and the extrinsic pathway can activate initiator caspases; initiator caspases then cleave and activate effector caspases. Effector caspases subsequently cleave substrate proteins which are essential for cell survival, such as PARP $[29,30]$.

PARP is proteolysed by caspase- 3 into two fragments, a 24-kDa DNA-binding fragment and an $89-\mathrm{kDa}$ catalytic fragment [24]. The cleavage of PARP is critical for apoptosis because it can prevent apoptosis induced by energy depletion and cell survival induced by DNA repair [31, 32]. The results further confirmed that TMPO knockdown promoted apoptosis. The new targets for GBM therapy are critical; inhibition of TMPO could induce apoptosis, suggesting it might be a novel target for GBM treatment.

\section{Conclusions}

This study found TMPO is significantly upregulated in GBM tissues. Functional analysis indicated that knockdown of TMPO suppressed GBM cell proliferation by inducing cell cycle arrest and apoptosis. Although the precise mechanisms are not yet fully understood, this finding suggests that TMPO might play an important role in regulating the proliferation of glioma cells and serve as a new target for GBM treatment.

\section{Acknowledgements}

The authors thank the staff of the Department of Neurosurgery at Shanghai Jiao Tong University Affiliated Sixth People's Hospital and School of Medicine, Shanghai Jiao Tong University, for their great support.

\section{Funding}

This project received seed funding grants from the National Natural Science Foundation of China (grant no. 81271383, 81471245); the Shanghai Science and Technique Committee (grant no.13411951401); and the Shanghai Municipal Health Bureau project (grant no. 20114242). The provider of the financial support was not involved in the study design, collection, analysis, and interpretation of the data; in the writing of the manuscript; and in the decision to submit the manuscript for publication.

Availability of data and materials

The authors wish to share their data on reasonable request.

\section{Authors' contributions}

LZ performed the vector construction experiments and drafted the manuscript. GW participated in the lentivirus package experiment. SWC and JD participated in the cellular function experiments. SMJ and HLC participated in the data analysis and figure format. HLT participated in the research design and reviewed the literature and the data mining. All authors read and approved the final manuscript.

\section{Competing interests}

The authors declare that they have no competing interests.

Consent for publication

Not applicable

Ethics approval and consent to participate Not applicable 
Received: 1 April 2016 Accepted: 4 October 2016 Published online: 19 October 2016

\section{References}

1. Stupp R, Mason WP, van den Bent MJ, Weller M, Fisher B, Taphoorn MJ, Belanger K, Brandes AA, Marosi C, Bogdahn U, et al. Radiotherapy plus concomitant and adjuvant temozolomide for glioblastoma. N Engl J Med. 2005:352:987-96.

2. Gallego O. Nonsurgical treatment of recurrent glioblastoma. Curr Oncol. 2015;22:e273-81

3. Preusser M, Lim M, Hafler DA, Reardon DA, Sampson JH. Prospects of immune checkpoint modulators in the treatment of glioblastoma. Nat Rev Neurol. 2015:11:504-14.

4. Gilbert MR, Dignam JJ, Armstrong TS, Wefel JS, Blumenthal DT, Vogelbaum MA, Colman H, Chakravarti A, Pugh S, Won M, et al. A randomized trial of bevacizumab for newly diagnosed glioblastoma. N Engl J Med. 2014;370:699-708

5. Chinot OL, Wick W, Mason W, Henriksson R, Saran F, Nishikawa R, Carpentier AF, Hoang-Xuan K, Kavan P, Cernea D, et al. Bevacizumab plus radiotherapy-temozolomide for newly diagnosed glioblastoma. N Engl J Med. 2014;370:709-22.

6. Berger R, Theodor L, Shoham J, Gokkel E, Brok-Simoni F, Avraham KB, Copeland NG, Jenkins NA, Rechavi G, Simon AJ. The characterization and localization of the mouse thymopoietin/lamina-associated polypeptide 2 gene and its alternatively spliced products. Genome Res. 1996;6:361-70.

7. Dechat T, Vlcek S, Foisner R. Review: lamina-associated polypeptide 2 isoforms and related proteins in cell cycle-dependent nuclear structure dynamics. J Struct Biol. 2000;129:335-45.

8. Brachner A, Foisner R. Lamina-associated polypeptide (LAP)2 alpha and other LEM proteins in cancer biology. Adv Exp Med Biol. 2014;773:143-63.

9. Somech R, Gal-Yam EN, Shaklai S, Geller O, Amariglio N, Rechavi G, Simon AJ. Enhanced expression of the nuclear envelope LAP2 transcriptional repressors in normal and malignant activated lymphocytes. Ann Hematol. 2007;86:393-401.

10. Kim HJ, Hwang SH, Han ME, Baek S, Sim HE, Yoon S, Baek SY, Kim BS, Kim $\mathrm{JH}$, Kim SY, Oh SO. LAP2 is widely overexpressed in diverse digestive tract cancers and regulates motility of cancer cells. PLoS One. 2012;7:e39482.

11. Rhodes DR, Yu J, Shanker K, Deshpande N, Varambally R, Ghosh D, Barrette T, Pandey A, Chinnaiyan AM. ONCOMINE: a cancer microarray database and integrated data-mining platform. Neoplasia. 2004;6:1-6.

12. French PJ, Swagemakers SM, Nagel JH, Kouwenhoven MC, Brouwer E, van der Spek P, Luider TM, Kros JM, van den Bent MJ, Sillevis Smitt PA. Gene expression profiles associated with treatment response in oligodendrogliomas. Cancer Res. 2005;65:11335-44.

13. Liang $Y$, Diehn M, Watson N, Bollen AW, Aldape KD, Nicholas MK, Lamborn KR, Berger MS, Botstein D, Brown PO, Israel MA. Gene expression profiling reveals molecularly and clinically distinct subtypes of glioblastoma multiforme. Proc Natl Acad Sci U S A. 2005:102:5814-9.

14. Murat A, Migliavacca E, Gorlia T, Lambiv WL, Shay T, Hamou MF, de Tribolet N, Regli L, Wick W, Kouwenhoven MC, et al. Stem cell-related "self-renewal" signature and high epidermal growth factor receptor expression associated with resistance to concomitant chemoradiotherapy in glioblastoma. J Clin Oncol. 2008;26:3015-24.

15. Shai R, Shi T, Kremen TJ, Horvath S, Liau LM, Cloughesy TF, Mischel PS, Nelson SF. Gene expression profiling identifies molecular subtypes of gliomas. Oncogene. 2003;22:4918-23.

16. Sun L, Hui AM, Su Q, Vortmeyer A, Kotliarov $Y$, Pastorino S, Passaniti A, Menon J, Walling J, Bailey R, et al. Neuronal and glioma-derived stem cell factor induces angiogenesis within the brain. Cancer Cell. 2006;9:287-300.

17. Pomeroy SL, Tamayo P, Gaasenbeek M, Sturla LM, Angelo M, McLaughlin ME, Kim JY, Goumnerova LC, Black PM, Lau C, et al. Prediction of central nervous system embryonal tumour outcome based on gene expression. Nature. 2002:415:436-42.

18. Rhodes DR, Kalyana-Sundaram S, Mahavisno V, Varambally R, Yu J, Briggs BB, Barrette TR, Anstet MJ, Kincead-Beal C, Kulkarni P, et al. Oncomine 3.0: genes, pathways, and networks in a collection of 18,000 cancer gene expression profiles. Neoplasia. 2007;9:166-80.

19. Livak KJ, Schmittgen TD. Analysis of relative gene expression data using real-time quantitative PCR and the 2(-Delta Delta C(T)) Method. Methods. $2001 ; 25: 402-8$
20. Zhang J, Liang Q, Lei Y, Yao M, Li L, Gao X, Feng J, Zhang Y, Gao H, Liu DX, et al. SOX4 induces epithelial-mesenchymal transition and contributes to breast cancer progression. Cancer Res. 2012;72:4597-608.

21. Shen G, Jia H, Tai Q, Li Y, Chen D. miR-106b downregulates adenomatous polyposis coli and promotes cell proliferation in human hepatocellular carcinoma. Carcinogenesis. 2013;34:211-9.

22. Fernandes-Alnemri T, Litwack G, Alnemri ES. CPP32, a novel human apoptotic protein with homology to Caenorhabditis elegans cell death protein Ced-3 and mammalian interleukin-1 beta-converting enzyme. J Biol Chem. 1994;269:30761-4

23. Nicholson DW, Ali A, Thornberry NA, Vaillancourt JP, Ding CK, Gallant M, Gareau Y, Griffin PR, Labelle M, Lazebnik YA, et al. Identification and inhibition of the ICE/CED-3 protease necessary for mammalian apoptosis. Nature. 1995;376:37-43.

24. Oliver FJ, de la Rubia G, Rolli V, Ruiz-Ruiz MC, de Murcia G, Murcia JM. Importance of poly(ADP-ribose) polymerase and its cleavage in apoptosis. Lesson from an uncleavable mutant. J Biol Chem. 1998;273:33533-9.

25. Dechat T, Gotzmann J, Stockinger A, Harris CA, Talle MA, Siekierka JJ, Foisner R. Detergent-salt resistance of LAP2alpha in interphase nuclei and phosphorylation-dependent association with chromosomes early in nuclear assembly implies functions in nuclear structure dynamics. EMBO J. 1998:17:4887-902.

26. Rieder CL. Mitosis in vertebrates: the G2/M and M/A transitions and their associated checkpoints. Chromosom Res. 2010;19:291-306.

27. Groth A, Rocha W, Verreault A, Almouzni G. Chromatin challenges during DNA replication and repair. Cell. 2007;128:721-33.

28. Boonstra J, Post JA. Molecular events associated with reactive oxygen species and cell cycle progression in mammalian cells. Gene. 2004;337:1-13.

29. Keoni CL, Brown TL. Inhibition of apoptosis and efficacy of pan caspase inhibitor, Q-VD-OPh, in models of human disease. J Cell Death. 2015;8:1-7.

30. Mcllwain DR, Berger T, Mak TW. Caspase functions in cell death and disease. Cold Spring Harb Perspect Biol. 2013;5:a008656.

31. D'Amours D, Sallmann FR, Dixit VM, Poirier GG. Gain-of-function of poly(ADP-ribose) polymerase-1 upon cleavage by apoptotic proteases: implications for apoptosis. J Cell Sci. 2001;114:3771-8.

32. Heeres JT, Hergenrother PJ. Poly(ADP-ribose) makes a date with death. Curr Opin Chem Biol. 2007:11:644-53.

\section{Submit your next manuscript to BioMed Central and we will help you at every step:}

- We accept pre-submission inquiries

- Our selector tool helps you to find the most relevant journal

- We provide round the clock customer support

- Convenient online submission

- Thorough peer review

- Inclusion in PubMed and all major indexing services

- Maximum visibility for your research

Submit your manuscript at www.biomedcentral.com/submit
) Biomed Central 